\title{
Administration of a Second Dose Antivenom in the Early Period: Is It Effective in Scorpion Stings?
}

\author{
回Çiğdem El1, 圆Mehmet Emin Çelikkaya² \\ ${ }^{1}$ Hatay Mustafa Kemal University Faculty of Medicine, Department of Pediatrics, Hatay, Turkey \\ ${ }^{2}$ Hatay Mustafa Kemal University Faculty of Medicine, Department of Pediatric Surgery, Hatay, Turkey
}

\begin{abstract}
Aim: It has been known for years that the toxic effects of scorpion envenomation can be fatal. Scorpion antivenom administration reduces the severity of systemic toxicity and fatal complications resulting from envenomation. In cases where clinical progression is poor, a second dose of antivenom can be applied. We aimed to investigate the effectiveness of a second dose of antivenom in this study.

Materials and Methods: One hundred patients between 0-17 years who were followed up due to scorpion stings or poisonings in Hatay Mustafa Kemal University, Faculty of Medicine, Department of Pediatrics between October 2016 and March 2018 were analyzed for age, gender, season, site of scorpion stings, clinical findings, treatment, follow-up steps and the effects of a second dose of antivenom on clinical progression retrospectively.

Results: Of the total 100 patients, 45 were female (45\%) and 55 were male (55\%). The average age of the patients was 3.5 years. Sting locations in order of frequency were as follows; feet, hands, legs, arms, head-neck, genital area. Single dose antivenom was given to 26 patients and a second dose was given to the remaining 74 patients. All patients recovered except two patients who were referred with cardiopulmonary insufficiency and passed away.

Conclusion: We observed that early antivenom therapy reduces the risk of developing systemic toxicity and also an administered second dose of antivenom corrects systemic findings. We think that the second dose of antivenom should be applied at the $8^{\text {th }}$ hour especially in pediatric patients with ongoing serious systemic findings and all patients should be observed for at least 24 hours.
\end{abstract}

Keywords: Clinical manifestation, envenomation, scorpion sting, second dose antivenom

\section{Introduction}

It has been known for years that the toxic effects of scorpion envenomation can be fatal. Every year, more than a million people suffer from scorpion stings all around the world. It is an important public health problem in South America, North Africa and Asian countries (1,2). Envenoming due to scorpion venom leads to excessive parasympathetic and sympathetic stimulation (3). These poisonings can cause complications ranging from local skin findings such as pain, redness, and pruritus to fatal complications such as heart failure and pulmonary edema (4-6). The progression of poisonings due to scorpion stings is more severe in children than adults. Cardiorespiratory complications are the most important cause of mortality in children $(1,2,6)$. For this reason, it is recommended that all children with scorpion stings should be hospitalized and monitored for at least 24 hours $(1,4,6-8)$. The size of the scorpion, amount of venom in its secretion, the age of the child and body region stung by the scorpion affect the mortality rate due to envenomation (8-10).

\section{Address for Correspondence}

Mehmet Emin Çelikkaya, Hatay Mustafa Kemal University Faculty of Medicine, Department of Pediatric Surgery, Hatay, Turkey Phone: +90 5373324143 E-mail: eminctf@hotmail.com ORCID: orcid.org/0000-0003-3324-4960

Received: 09.04.2019 Accepted: 24.07.2019

${ }^{\odot}$ Copyright 2020 by Ege University Faculty of Medicine, Department of Pediatrics and Ege Children's Foundation The Journal of Pediatric Research, published by Galenos Publishing House. 
Scorpion antivenom is the only specific treatment of envenomation. It has been reported in the literature that administration of antivenom resolved the systemic manifestations within hours and reduced the mortality rate even in severe envenoming. Therefore, it must be administered as early as possible (11-14).

At the ADELF congress (2009) on the management of scorpion envenomation, consensus was reached by the scientists who participated from endemic areas (Algeria, Argentina, Bolivia, Egypt, India, Israel, Mexico, Morocco, Saudi Arabia, Tunisia and Turkey). According to this consensus, scorpion stings are divided into 3 classes (Table I). Antivenom therapy was suggested for patients who are in the class 2 and class 3 groups (13).

We aimed to investigate the effects of a second dose of antivenom administration on patients with impaired clinic at the 8th hour despite the administration of a first dose of antivenom.

\section{Material and Methods}

\section{Study Design}

This study was a retrospectively designed, observational, single-centre clinical study at the Pediatric Emergency Department of Hatay Mustafa Kemal University, Turkey, between October 2016 and March 2018. All patients (ages 0 to 18 years) who were diagnosed and treated for poisonings due to scorpion stings were screened in this study. Patients who had only mild local manifestation (class 1 patients) and were over 18 years old were excluded. Those patients with incomplete information were contacted using their contact details obtained from the hospital information system. Patients whose information could not be completed were excluded from this study. Patients were divided into three groups.

Group 1: Patients with class 1 clinical manifestation who recovered after being given a single dose of antivenom therapy.

Table I. Three classes of scorpion envenomation

Class I: Local findings (pain, edema, redness, itching without systemic involvement)

Class II: Systemic involvement (vomiting, sweating, hypersalivation, priapism, cold extremities, mydriasis, hypertension)

Class III: Arrhythmia, bradycardia, cardiogenic failure, cardiovascular collapse, dyspnoea, Glasgow coma score $<6$ (without sedation), hypotension, pulmonary edema, neurological failure, paralysis
Group 2: Patients with class 2 or class 3 clinical manifestation who were administered a second dose of antivenom therapy at the eighth hour.

Group 3: Patients with class 2 or class 3 clinical manifestation who had a late admission to hospital and thus were administered a second dose of antivenom therapy between the $24^{\text {th }}$ and $36^{\text {th }}$ hours.

\section{Data Collection}

The data of the patients were obtained from hospital records and entered into a database in Microsoft office excel. The main variables obtained were demographic data (age, gender), season in which the sting occurred, type of scorpion, site of scorpion sting, first intervention practices by the individual family, local findings at the site of the sting and systemic findings after the scorpion sting in the initial examination and during the treatment/follow up steps, the effects of the second dose of antivenom on clinical progression and laboratory data. Indications of the administration of the first and second dose of scorpion antivenom, therapy time and adverse effects were recorded.

\section{Scorpion Identification}

Scorpions which were killed by the individual or their family were identified. The species brought by the family were transferred in glass jars, containing 70\% ethanol, which were labeled and numbered with the date of sampling and the location. In a laboratory at the Department of Faculty of veterinary medicine, the scorpions were identified.

\section{Laboratory Analysis}

Laboratory analyses including complete blood count (Mindray BC 6800 hematology analyzer), electrolyte values, liver, kidney function tests, and cardiac markers (creatine kinase MB, troponin I) (Abbott, architect c 8000, USA); coagulation parameters and also electrocardiography and echocardiography were evaluated.

\section{Treatment}

All patients in this study were treated based on evidencebased medicine guidelines. After initial evaluations in the pediatric emergency department, vital signs [oxygen saturation, blood pressure, heart rhythm and pulses (central / peripheral)] of the all patients were carefully monitored and recorded every fifteen minutes.

All patients with severe local and systemic manifestation were treated with antivenom (scorpion antivenom specifically to neutralize the venom of the species Androctonus crassicauda) and tetanus prophylaxis. (Including 39 patients who were referred to our clinic 
from another health facility and who were untreated with antivenom and tetanus prophylaxis). Wound dressing and anti-biotherapy were performed in secondary bacterial infections such as cellulite.

Patients who had severe systemic findings such as arrhythmia, bradycardia, cardiogenic failure, cardiovascular collapse, dyspnea, Glasgow Coma score <6 (without sedation), hypotension, pulmonary edema, neurological failure or paralysis were followed up in intensive care. Second doses of antivenom were administered to patients who had continued systemic clinical manifestation after 8 hours despite the first dose of antivenom administration in the intensive care unit. Alpha blocker (doxazosin; Pfizer Pharmaceuticals, New York) and inotropic drugs (Dopamine, Dobutamine, Norepinephrine, Epinephrine,) were administered to those patients with heart failure. Additionally, patients with severe respiratory failure due to pulmonary edema or heart failure were supported by mechanical ventilation.

\section{Statistical Analysis}

Data were analyzed using SPSS for Windows 18.0 version. The differences between the groups were examined by Student's t-test. Categorical variables were evaluated by chi-square test. $\mathrm{P}<0.05$ was considered significant.

\section{Results}

During the nearly two year study period, a total of 100 patients with envenomation class 2 and above were admitted due to scorpion envenomation. 45 patients were female (45\%) and 55 patients were male (55\%). The median age of the patients was 3.5 years (19 months to 15 years).

Scorpion envenomation cases mostly occurred between May and September (71\%) and also peaked in July (22\%) and August (21\%). Scorpion stings were seen mostly on the lower limbs (50\%). Sting locations in order of frequency were as follows; feet, hands, legs, arms, head-neck, genital area (Figure 2). Three patients were stung more than once

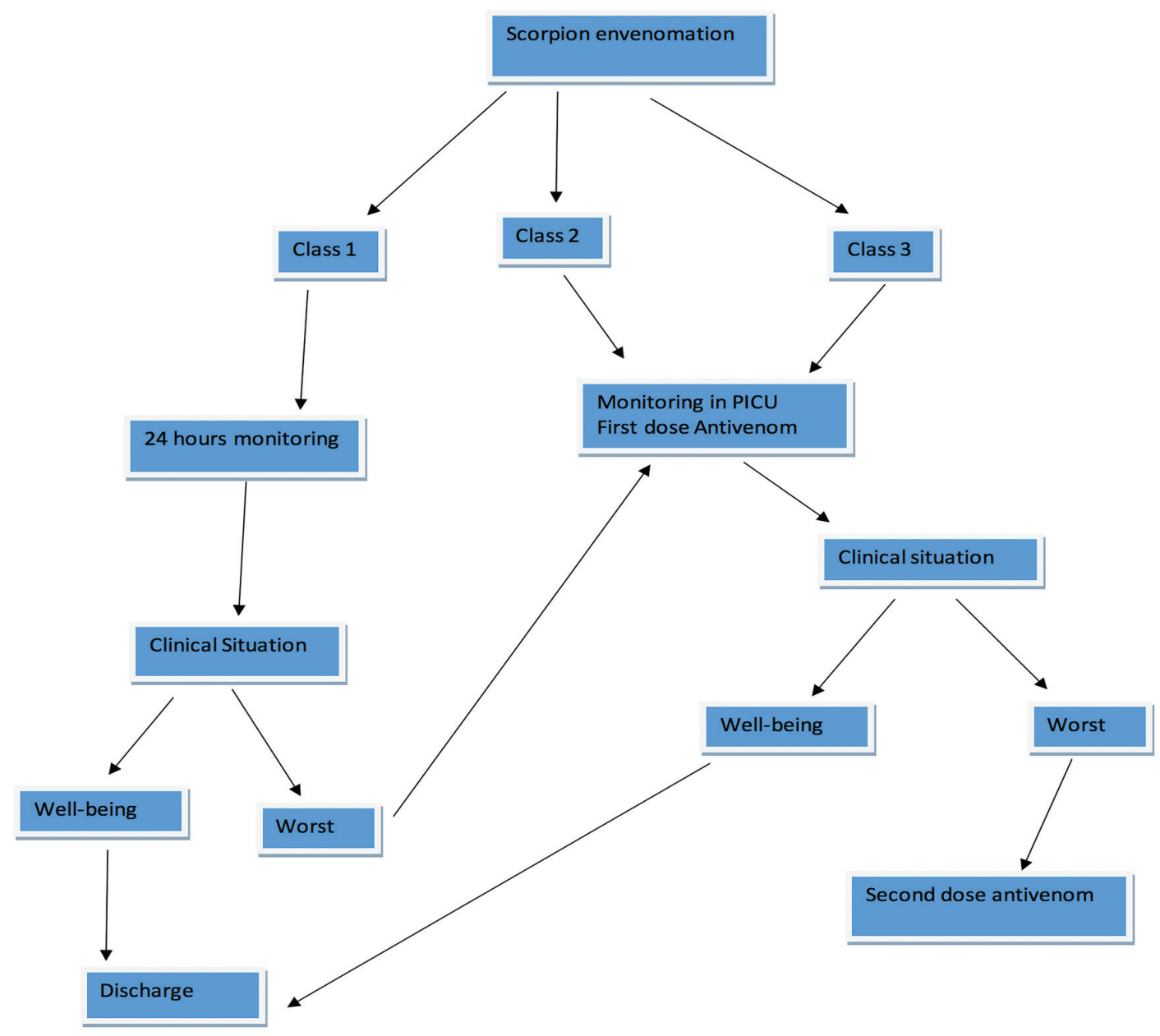

Figure 1. Scorpion envenomation management diagram 
simultaneously (hand and thumb in one patient, dorsal of foot and heel in one patient and plantar of foot and toe in one patient).

When comparing group 2 and group 3 patients; admission time to the health facility, hospitalization time and intubation necessity were found to be significantly different (Table II).

In our study, 38 of all patients in group 2 were taken to the health facility an average of 3.9 hours after the scorpion sting. The 36 patients in group 3 were taken to the health facility after an average of 14.6 hours following the scorpion sting.

Although the second dose of antivenom was given to the group 2 patients at the eighth hour, the second dose of antivenom was given to the group 3 patients from 24 to

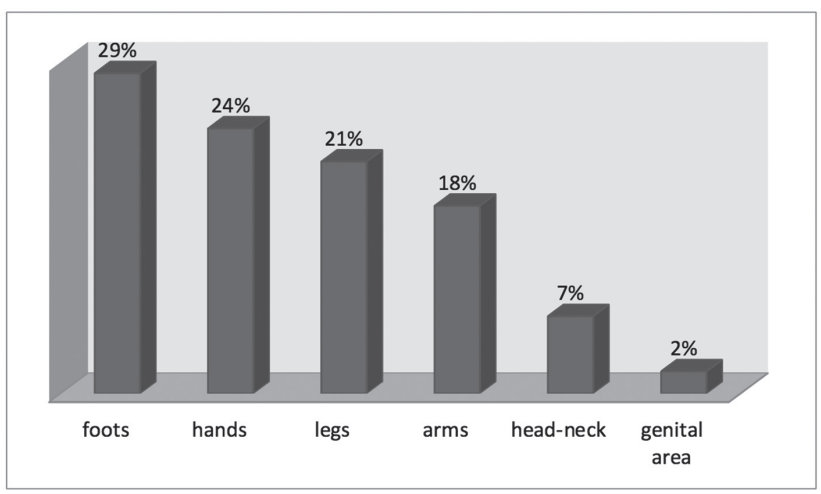

Figure 2. Frequency of sting locations (3\% of patients were stung more than once)

Table II. Comparison of group 2 and group 3 patients

\begin{tabular}{|c|c|c|c|}
\hline & Group 2 & Group 3 & $\begin{array}{l}\text { p (Group } \\
2 \text { and } 3 \text { ) }\end{array}$ \\
\hline $\begin{array}{l}\text { The number of } \\
\text { patients }\end{array}$ & 38 & $36^{*}$ & \\
\hline $\begin{array}{l}\text { Healthy at facility } \\
\text { admission (hour) }\end{array}$ & 3.9 & 14.6 & $<0.01$ \\
\hline $\begin{array}{l}\text { Intensive care } \\
\text { monitoring }\end{array}$ & $38(100 \%)$ & $36(100 \%)$ & $>0.05$ \\
\hline $\begin{array}{l}\text { Hospitalization time } \\
\text { (hour) }\end{array}$ & $36.3(32-48)$ & $102.4(96-120)$ & $<0.01$ \\
\hline Intubation necessity & $7(18 \%)$ & $12(33 \%)$ & 0.048 \\
\hline $\begin{array}{l}\text { PRISM score } \\
\text { (median) }\end{array}$ & $16.3(14-20)$ & $23.4(21-27)$ & 0.042 \\
\hline PIM score (median) & $7.1(2-14)$ & $11.6(8-19)$ & 0.026 \\
\hline Mortality & 0 & $2(5.5 \%)$ & $>0.05$ \\
\hline
\end{tabular}

36 hours after the sting due to their late admission to the health facility.

None of the patients developed adverse reactions to the scorpion antivenom.

Initial systemic clinical findings were as follows; pain/ edema, excessive sweating, hypersalivation, nausea/ vomiting, abdominal pain, tachycardia, hypertension, dyspnoea, cold extremities, loss of consciousness, priapism, hypotension, mydriasis, cardiac failure and pulmonary edema (Table III).

Clinical findings at the $8^{\text {th }}$ hour after admission to the clinic were as follows; hypersalivation, excessive sweating, pain/edema, cold extremities, abdominal pain, tachycardia, hypotension, loss of consciousness, cellulitis, mydriasis, cardiac failure, pulmonary edema, fever and priapism (Table III).

In total, nine patients had cardiopulmonary insufficiency. These patients had abnormal echocardiographic findings (systolic dysfunction, decreased ejection fraction). Two of these patients were referred with the cardiopulmonary insufficiency while severe cardiac failure and pulmonary edema developed in seven of these patients during monitoring and they progressed from class 2 to class 3. The two patients who were referred with cardiopulmonary insufficiency died (Table II). The admission to emergency department and first administered antivenom time for both these patients were longer than 10 hours.

\section{Discussion}

The incidence of scorpion envenomation is more than one million a year worldwide. Three thousand of these cases result in death $(1,4)$. Especially in childhood, scorpion stings are an important public health problem in terms of morbidity and mortality $(1,2,6)$. The risk of developing mortal

Table III. Clinical findings

\begin{tabular}{|l|l|l|l|}
\hline $\begin{array}{l}\text { Initial systemic clinical } \\
\text { findings }\end{array}$ & $\begin{array}{l}\mathbf{n} \\
\mathbf{( \% )}\end{array}$ & $\begin{array}{l}\text { Clinical findings at } \\
\mathbf{8}^{\text {th }} \text { hour }\end{array}$ & $\begin{array}{l}\mathbf{n} \\
\mathbf{( \% )}\end{array}$ \\
\hline pain/edema & 52 & hypersalivation & 51 \\
excessive sweating & 46 & excessive sweating & 51 \\
hypersalivation & 42 & pain/edema & 47 \\
nausea/ vomiting & 42 & cold extremities & 43 \\
abdominal pain & 38 & abdominal pain & 42 \\
tachycardia & 34 & tachycardia & 38 \\
hypertension & 29 & hypotension & 36 \\
dyspnoea & 23 & loss of consciousness & 19 \\
cold extremities & 23 & cellulitis & 13 \\
loss of consciousness & 12 & mydriasis & 9 \\
priapism & 9 & cardiac failure & 9 \\
hypotension & 8 & pulmonary edema & 9 \\
mydriasis & 6 & fever & 8 \\
cardiac failure & 2 & priapism & 4 \\
pulmonary edema & 2 & & \\
\hline
\end{tabular}


complications in children is higher because of the amount of toxin is greater according to body weight $(1,2,6)$. Therefore, even if there is no evidence of envenomation, all patients with scorpion stings should be followed up for at least 24 hours (14-17). The clinical stages of envenomation can be very different in childhood. The nervous system is affected by scorpion venom (sympathetic/parasympathetic); and this can lead to tachycardia, sweating, hypersalivation, hyperthermia, tachypnea, vomiting, pulmonary edema, fasciculations, priapism, arrhythmia, hypertension, bradycardia, hypotension, bronchoconstriction or even cardiopulmonary insufficiency $(1,2,5,18)$. Cardiogenic shock and pulmonary edema associated with myocarditis, which is thought to be caused by the direct effect of scorpion venom or due to the response to autonomic storm, is the most common cause of death due to scorpion stings in children $(1,2,17-19)$.

In our study, two patients who were late admission to the emergency department with severe cardiac failure and pulmonary edema died. These data suggested that early admission to an emergency department and a first dose being administered as early as possible and, when necessary, a second dose of scorpion antivenom reduces mortality in scorpion envenomation.

The most common scorpion species in our region are Mesobuthus nigrocinctus, Scorpio maurus and Compshobuthus schmiedeknechti. The scorpion antivenom used in our study, which is specifically to neutralize the venom of the species Androctonus crassicauda is also effective against the venom of these three species in our region (20).

Scorpion stings are common, especially during the summer months in areas with temperate climates and they are an important public health issue (1,3,13-19). In our study, Scorpion envenomation cases mostly occurred (71\%) between May and September and also peaked in July (22\%) and August (21\%).

In epidemiological studies, it has been reported that the extremities are the most frequently stung area in scorpion sting cases $(16,18,19)$. In our study, similar to the literature, the most stung region was the extremities (91\%) (Figure 2). For this reason, we think that the open areas of the body should be more protected.

Recommended first interventions in scorpion stings are as follows; washing the site of sting with soapy water, bandaging of the extremity (should not obstruct the vascular circulation to prevent toxin spread), a cold application to the extremity, immobilization of the extremity and as early as possible admission to an emergency department. Tourniquets are not recommended because they can block vascular circulation $(1,19,20)$. In our study, it was learned that 37 of the cases were washed with soapy water and 21 had bandaging of the extremities. These data draw attention to the fact that it is important to raise awareness about envenomation among people especially those living in endemic areas.

Medical treatments include intravenous fluid therapy, analgesics, antibiotics, alpha blockers and inotropic drugs, tetanus prophylaxis and also scorpion antivenom $(1,12,13,19,20)$. Prozacin (alpha-adrenergic blocker) is effective in the treatment of cardiovascular complications of scorpion venom $(1,13,19,21-23)$. Doxazosin, such as prazosin, can also be used in autonomic storm such as tachycardia, hypertension, hypersalivation, and excessive sweating $(19,24)$. In our study, doxazosin was used in 74 patients with autonomic storm, 36 of whom progressed from mild envenomation (class 2) to severe envenomation (class 3).

The administered antivenom in scorpion envenomation is controversial. While some researchers have argued that antivenom is not beneficial, some researchers suggest that antivenom reduces morbidity and mortality $(4,11,12,19,25)$. It has been reported in some studies that allergic complications may develop due to antivenom. There is no consensus about antivenom administration dose and time. However, in some studies, repeated administration of antivenom is recommended in patients who have continued and deteriorating clinical manifestation $(4,11-13,26)$.

In our study, all patients were treated with a first dose antivenom. Seventy-four patients with class 3 envenomation were administered a second dose of antivenom. In total, nine patients had cardiopulmonary insufficiency. The two patients who were referred with the cardiopulmonary insufficiency died. Both the time of admission to the emergency department and the time of the first administered antivenom of these two patients were longer than 10 hours (Table II).

According to the different geographical regions in the world, the mortality rate has been reported in the literature to be between $3.1 \%$ and $38.1 \%(1,19,22,26,27)$. In our study, the mortality rate was $2 \%$. The remarkable thing is that although all patients in our study were class 2 and class 3 envenomation, our mortality rate was lower than the literature. These data showed us that early admission to an emergency department and an early administration of a second dose of antivenom can prevent mortality and morbidity caused by scorpion envenomation. 


\section{Conclusions}

Consequently, this study showed that early admission to an emergency department and the as early as possible first administration of antivenom and, when required, a second dose of antivenom are safe and may prevent complications and reduce mortality caused by scorpion envenomation.

\section{Disclosure statement}

The authors declare no conflicts of interest, funding, or financial benefit arising from this study.

\section{Ethics}

Ethics Committee Approval: Ethics approval was received from Hatay Mustafa Kemal University Research Ethics Committee (approval number: 14096738-108, date: 10.12.2018)

Informed Consent: Retrospective study.

Peer-review: Externally and internally peer-reviewed.

\section{Authorship Contributions}

Concept: Ç.E., Design: Ç.E., Data Collection or Processing: M.E.Ç., Writing: M.E.Ç.

Conflict of Interest: The authors have no conflicts of interest relevant to this article to disclose.

Financial Disclosure: The authors have no financial relationships relevant to this article to disclose.

\section{References}

1. Kliegman RM, St Geme JW, Schor NF eds. Nelson Textbook of PEDIATRICS, 20 ed. Philadelphia: ELSEVIER 2016;3457-8.

2. Bahloul M, Chabchoub I, Chaari A, et al. Scorpion envenomation among children: clinical manifestations and outcome (analysis of 685 cases). Am J Trop Med Hyg 2010;83:1084-92.

3. Koca E, Öztürk Ö. Akrep Sokması Nedeniyle Yoğun Bakımda Takip Ettiğimiz 108 Hastadaki Tecrübemiz. KÜ Tıp Fak Derg 2015;17:14-20.

4. Chippaux IP, Goyffon M. Epidemiology of scorpionism: a global appraisal. Acta Trop 2008;107:71-9.

5. Müller G). Scorpionism in South Africa: a report of 42 serious scorpion envenomations. S Afr Med / 1993;83:405-11.

6. Ghalim N, El-Hafny B, Sebti F, et al. Scorpion envenomation and serotherapy in Morocco. Am J Trop Med Hyg 2000;62:277-83.

7. Isbister GK, Bawaskar HS. Scorpion envenomation. N Engl I Med 2014;371:457-63.

8. Pandi K, Krishnamurthy S, Srinivasaraghavan R, Mahadevan S. Efficacy of scorpion antivenom plus prazosin versus prazosin alone for Mesobuthus tamulus scorpion sting envenomation in children: a randomised controlled trial. Arch Dis Child 2014;99:575-80.

9. Bawaskar, H.S. and P.H. Bawaskar, Scorpion sting: update. I Assoc Physicians India, 2012. 60(1): p. 46-55.
10. Farghly WM, Ali FA. A clinical and neurophysiological study of scorpion envenomation in Assiut, Upper Egypt. Acta Paediatr 1999;88:290-4.

11. Dudin AA, Rambaud-Cousson A, Thalji A, Juabeh II, Abu-Libdeh B. Scorpion sting in children in the Jerusalem area: a review of 54 cases. Ann Trop Paediatr 1991;11:217-23.

12. Theakston RD, Warrell DA, Griffiths E. Report of a WHO workshop on the standardization and control of antivenoms. Toxicon 2003;41:541-57.

13. Khattabi A, Soulaymani-Bencheikh R, Achour S, Salmi LR; Scorpion Consensus Expert Group. Classification of clinical consequences of scorpion stings: consensus development. Trans R Soc Trop Med Hyg 2011;105:364-9.

14. Abimannane $A$, Rameshkumar $R$, Satheesh $P$, Mahadevan S. Second Dose of Scorpion Antivenom in Children with Indian Red Scorpion (Mesobuthus tamulus) Sting Envenomation. Indian Pediatr 2018;55:315-318.

15. Hering SE, Jurca M, Vichi FL, Azevedo-Marques MM, Cupo P. Reversible cardiomyopathy'in patients with severe scorpion envenoming by Tityus serrulatus: evolution of enzymatic, electrocardiographic and echocardiographic alterations. Ann Trop Paediatr 1993;13:173-82.

16. Nhachi CF, Kasilo OM. Poisoning due to insect and scorpion stings/bites. Hum Exp Toxicol 1993;12:123-5.

17. Osnaya-Romero N, de Jesus Medina-Hernández T, FloresHernández SS, León-Rojas G. Clinical symptoms observed in children envenomated by scorpion stings, at the children's hospital from the State of Morelos, Mexico. Toxicon 2001;39:781-5.

18. Curry SC, Vance MV, Ryan PJ, Kunkel DB, Northey WT. Envenomation by the scorpion Centruroides sculpturatus. I Toxicol Clin Toxicol 1983-1984;21:417-49.

19. Sinha M, Quan D, McDonald FW, Valdez A. Cost Minimization Analysis of Different Strategies of Management of Clinically Significant Scorpion Envenomation Among Pediatric Patients. Pediatr Emerg Care 2016;32:856-62.

20. Hıfzıssıhha, R.S.H.M.B. and M. Müdürlüğü, TC Sağlık Bakanlığı, Birinci Basamağa Yönelik Zehirlenmeler Tanı ve Tedavi Rehberleri. 2007. Bakanlık Yayını ISBN: p. 978-975.

21. Karnad D. Haemodynamic patterns in patients with scorpion envenomation. Heart 1998;79:485-9.

22. Natu V, Kamerkar SB, Geeta K, et al. Efficacy of anti-scorpion venom serum over prazosin in the management of severe scorpion envenomation. J Postgrad Med 2010;56:275-80.

23. Gupta V. Prazosin: a pharmacological antidote for scorpion envenomation. J Trop Pediatr 2006;52:150-1.

24. Christiansson L. Anesthesia for Pheochromocytoma. Anesthesia for Urologic Surgery 2014;147-75.

25. Chippaux IP, Goyffon M. Epidemiology of scorpionism: a global appraisal. Acta Trop 2008;107:71-9.

26. Abroug F, ElAtrous S, Nouira S, Haguiga H, Touzi N, Bouchoucha S. Serotherapy in scorpion envenomation: a randomised controlled trial. Lancet 1999;354:906-9.

27. Dehghani R, Rafinejad J, Fathi B, Shahi MP, Jazayeri M, Hashemi A. A Retrospective Study on Scropionism in Iran (2002-2011). Arthropod Borne Dis 2017;11:194-203. 